\title{
A Summary of Research on the Training Path of Applied Big Data Talents Under the Background of New Engineering
}

\author{
Weiwei Gong ${ }^{1, a}$, Jianjun Huang ${ }^{1, b}$ and Yingjian Xiao ${ }^{1, c}$
}

\begin{abstract}
${ }^{I}$ School of Computer Information Engineering, Nanchang Institute of Technology, Nanchang, Jiangxi, China

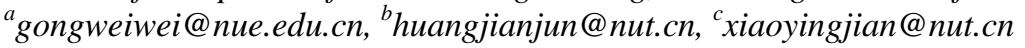

\begin{abstract}
With the continuous development of big data technology and its wide application in all walks of life, big data has officially become a national strategy. However, because of the urgent need for the research ability and quality innovation talents of big data science, the cultivation of top-notch innovation talents who are engaged in big data processing and high-performance computing has become the most urgent problem. The construction of new engineering course is to solve the deep-seated problem that engineering professional education lags the development of new economy and new technology. In this paper, based on the practice of the course construction of big data specialty, and on the summary of the views of Wu Hejun, Ding Ying, Zhang Renzhi, Wang Chao, Ma Jiaxing, etc., the organic integration of new subjects and basic subjects in specialty construction is put forward, so as to adapt to and lead the construction process of new engineering.
\end{abstract}

Keywords: big data, new engineering, talent training

\section{INTRODUCTION}

The new engineering course is an all-round reflection on the current problems of engineering education and an upgrade in the whole field. It is a strategy to deal with the change of industrial structure caused by future industrial pattern and industrial pattern, and also an innovation of traditional engineering education pattern, system, theory and method. In addition, the world today is still in the third wave of the scientific and technological revolution. Network Technology has made the degree of globalization more universal, and big data is not only a large amount of data, but through the comprehensive analysis of big data, to obtain deeper, more intelligent, more valuable information. Therefore, big data analysis in the field of big data applications is particularly important. Analysis, judgment and classification are the primary research direction of application-oriented talents in the new background. Based on the influence of the development and upgrade of New Engineering, this paper discusses how to train the new applied big data talents, and grasps the most systematic and universal elements to deal with the social changes and changes and adapt to the development of new science and technology [3].

\section{EXISTING LOOPHOLES IN THE BIG DATA PROFESSIONAL TEACHING MODEL}

\subsection{Inadequate Teaching Infrastructure}

In recent years, although many colleges and universities have begun to set up big data programs and colleges' teaching goals in order to meet society's great demand for big data talents, for this discipline, which has just begun to be built, the infrastructure required is not perfect. As for the big data from the social industry, it can not be stored by one or several universities alone. It needs to carry out systematic investigation and investigation of all social strata and industries In order to carry out the big data analysis. This is an extremely large amount of research that requires the collaboration of society and universities to build the foundations of big data. In addition, students of big data need not only the basics of the data, but also learning tools and teaching facilities. At present, some colleges and universities, with their long-term vision advantage, have carried out scientific research projects, such as the establishment of educational platform, the sharing of educational resources and the data processing of computers. However, for universities lacking economic support and national research funding, the high level of infrastructure can not be achieved, which is a great obstacle to the development of this educational model.

\subsection{Lack of High Quality Teacher Reserves}

As the teaching of big data in universities is still in the embryonic stage, some teaching materials and knowledge structure of the system have not been established yet, which leads to the shortage of teachers. From the current practical classroom teaching, the teacher's knowledge transfer to students only involves surface theory, but lacks in-depth teaching involving practical operations. For students majoring in big data, teachers are indeed a foundation of their learning, and the demands of teachers are a direct reflection of the quality of students' learning. However, because universities are in the initial stage of big data teaching, some teachers have not received systematic training, and because big data has its unique cross-complexity, teachers are required to be proficient in multi-disciplinary knowledge, so as to achieve a great degree of big data professional teaching task [2]. 


\subsection{Imperfect Overall System of the Course}

Big data is an interdisciplinary subject, involving the application and promotion of many areas of society. Some colleges and universities, in order to meet the needs of society for talents, began to carry out teaching on big data in schools, but for the emerging big data teaching, its curriculum and subject guidance and other core curriculum arrangement is not mature, so that in the scope of the curriculum, only data collection processing, data management and storage and other basic knowledge and skills are taught, and the social urgent need for data exploration applications, etc. are rarely involved. As a result, many graduates of big data major can hardly touch the core position of big data work after they enter the society, but only stay in the basic work unit, so that the ability of this part of the staff can not be trained, the social development of big data is constrained [1].

\section{BIG DATA PROFESSIONAL COURSE CONSTRUCTION EXPLORATION}

The training goal of the major direction of big data is to enable students to systematically master the basic theories, knowledge, skills and methods of data science, statistics, artificial intelligence, etc., and to make students have better data engineering practice ability, strong learning ability and strong data research quality after the course study and practice. After graduation, students will be able to engage in large-scale database development and maintenance, data mining and analysis, business analysis and forecasting, industrial and agricultural products quality improvement and other related big data engineering applications, and become a composite talent in system design and development, algorithm development, data science research and teaching in data computing, artificial intelligence and related technologies[3]. The big data professional system capacity training requirements are divided into two levels:

(1) Master the basic knowledge of big data science; Master large-scale, heterogeneous, multi-source, multi-dimensional, distributed, structured and unstructured data storage technology and network data collection and distributed storage technology; Master the basic methods of formatted data analysis and mining, with the ability of data modeling and data visualization.

(2) Have a good understanding of supercomputer, highperformance computing, data center and other infrastructure; Have relatively systematic experience in big data engineering practice; Have strong use of machine learning methods and use advanced statistics for data analysis and statistics; Be able to comprehensively and efficiently apply parallel algorithms and computing resources such as GPU clusters, FPGA boards, etc. to solve real big data engineering problems [4].

\section{EXPLORE MEASURES TO OPTIMIZE THE TEACHING MODEL OF BIG DATA TODAY}

\subsection{The Cultivation of Talents Shall Focus on the Construction of the Teaching Staff}

In teaching, the teaching staff is one of the important paths of personnel training. The teacher, one who could propagate the doctrine, impart professional knowledge, and resolve doubts. The establishment of teaching objective and teaching method of new engineering education can not depend on the results of traditional market research and analysis, after all, the original results can not adapt to the rapid development of social reality. Therefore, it is necessary to grasp the future needs and development direction of the country and industry, and use this as the goal and basis of teaching and research, and form a professional team to establish systems and teaching methods through the establishment of relevant professionals of different disciplines and external scientific research institutions and enterprise experts. This should be mainly reflected in the new development, emerging and new state, and it is a breakthrough in the traditional thinking logic and the old-style education system. It may be important to coordinate the teaching resources and research results of all aspects of society, pay attention to the connection between the new engineering and traditional engineering teaching resources, and make innovative changes and transformations based on the needs of the new situation on the basis of highquality resources, so as to avoid the theoretical problems caused by the unsuitable and unsolvable problems caused by the excessive gap. In addition, the teachers should form a concrete feasible and practical analysis and demonstration, and make a reasonable overall plan according to the social and industrial development as well as the actual situation of the school's Talent Strategy Develop a talent training strategy that meets the needs. With the help of Internet big data, through the analysis and research of the teaching cases of new engineering in the past, through the universality and specialness of big data, individual and general, individual and group, to find out the teaching advantages and shortcomings behind the data, and then to carry out regular, substantive summary of teaching tasks[1].

\subsection{Precise Positioning to Train Talents from Reality}

Different schools in different areas have different teaching resources, teaching orientation and talent training objectives, according to the circumstances to achieve accurate positioning in order to achieve the heterogeneity , multi-level, multi-directional training of talent, this is also a concrete way to realize the training of applied big data talents[2].

Because of the inequality and particularity of professional orientation, school development history, teachers' scientific research team, etc., many colleges and universities have different development direction, professional social orientation, service direction and subject level, so colleges and universities should carry out the comprehensive development according to the actual situation of the school 


\section{REFERENCES}

play to different types of unique training programs, instead of blindly pursuing the rapid development and blindly study other colleges and universities talent strategy, while ignoring their own advantages and shortcomings. As a result of its long history of running schools, colleges and universities have accumulated a broad social base and formed a deep relationship with enterprises, especially in the employment of graduates, which has the best understanding of the various fields of the industry in which the campus is located. Therefore, according to the specific regional and field needs, colleges and universities should train new engineering talents, according to the actual needs and development of local enterprises and industries, to promote the integration, transformation, transformation and upgrading of the traditional engineering and science departments of the university. In addition, colleges and universities should keep up with the changes in national strategies and policies, make use of the welfare conditions given by the state in terms of talent training and talent demand, build bridges for new engineering students in schools, expand and increase their development space and opportunities for progress, and, in accordance with the requirements of national strategic objectives and tasks, cultivate the current industry and industry in urgent need of all levels and types of outstanding engineering and scientific and technological talent, reform teaching methods, vigorously cultivate the ability of talent innovation and dialectical thinking, take the initiative to lay out, set up, develop talent training programs, and then train the actual needs of society and the country of the application of big data talent.

\section{CONCLUSION}

The training of talents in big data should pay attention to the all-round development of morality, wisdom and body, and have the spirit of scientific humanism, innovative entrepreneurship and good professional ethics. Learners should have the ability to learn independently, practice innovation, algorithm analysis, algorithm design and computer programming, and they should cultivate the ability to apply information technology to massive data processing, so that they can solve some practical problems in their actual work. In addition, they need to be critical thinkers and team players, and master the statistics and mathematics required for data science and big data technologies Knowledge of computer, network, data processing, algorithm analysis, algorithm design and programming, and ability to solve engineering problems. They also need to have the ability to innovate their own knowledge, improve their ability to track and process big data information using new technologies, and become proficient in the acquisition, transmission, storage, processing, and analytical applications of Big Data Information. At last, they should have the design and development ability of big data engineering project, have certain ability and quality of big data science research, and eventually becomes an application-oriented and compound senior professional who can be engaged in big data mining, integration, analysis and processing, prediction, processing, service, development and utilization in all walks of life.
[1] Zhang Zhiren. "Research and practice of big data professional training program for local undergraduate colleges based on new engineering education," Computer Knowledge and Technology, 2019, 15, 79-81. (In Chinese) [2] Wang Chao. "Exploration on the Training Mode of University Big Data Professionals under the Background of New Engineering," THINKER'S VIEW, first half, Issue 6, 2019, 29-30. (In Chinese)

[3] Ma Jiaxing, "Research on the Training Path of Applied Big Data Talents under the Background of New Engineering," Shenzhou, Last Journal, 2019, Issue 10, 46-46. (In Chinese)

[4] Wu Hezhen, "Construction of Big Data Professional Course for New Engineering," Chinese University Teaching, 2019, Issue 4, 56-57. (In Chinese) 